\title{
Inhibition of miR-155-5p attenuates the valvular damage induced by rheumatic heart disease
}

\author{
ANG CHEN* ${ }^{*}$ JIANLIN WEN* ${ }^{*}$ CHUANGHONG LU, BEIYOU LIN, SHENGLIN XIAN, \\ FENG HUANG, YUNJIAO WU and ZHIYU ZENG
}

Department of Cardiology, The First Affiliated Hospital of Guangxi Medical University, Nanning, Guangxi 530021, P.R. China

Received June 4, 2019; Accepted November 20, 2019

DOI: $10.3892 /$ ijmm.2019.4420

\begin{abstract}
Autoimmunity is involved in the valvular damage caused by rheumatic heart disease (RHD). Increased evidence has linked microRNAs (miRNAs/miRs) to autoimmune disease. Signal transducer and activator of transcription 3 (STAT3) and sphingosine-1-phosphate receptor 1 (S1PR1) and suppressor of cytokine signaling 1 (SOCS1) have been widely studied for their roles in autoimmunity and inflammation. Thus, the current study aims to investigate the role played by miR-155-5p in RHD-induced valvular damage via the S1PR1, SOCS1/STAT3 and interleukin (IL)-6/STAT3 signaling pathways. An RHD rat model was induced by inactivated Group A streptococci and complete Freund's adjuvant. A recombinant adeno-associated virus (AAV-miR155-inhibitor) was used to inhibit the expression of miR-155-5p in the heart. Inflammation and fibrosis were assessed by hematoxylin and eosin staining and Sirius red staining. The expression of miR-155-5p in valvular tissues and serum exosomes was detected by reverse transcription-quantitative PCR. S1PR1, SOCS1, STAT3, phosphorylated STAT3, IL-6 and IL-17 protein expression was detected by western blotting and immunohistochemistry. The relationships between miR-155-5p and S1PR1 and SOCS1 were detected by dual luciferase assays. Cytokine concentrations were measured by ELISA. The expression of miR-155-5p in valve tissues and serum exosomes was increased along with decreased S1PR1 and activated SOCS1/STAT3 signaling in the RHD model. The expression of IL- 6 and IL-17 was increased in the valves and the serum. Dual luciferase assays
\end{abstract}

Correspondence to: Professor Zhiyu Zeng, Department of Cardiology, The First Affiliated Hospital of Guangxi Medical University, 6 Shuangyong Road, Nanning, Guangxi 530021, P.R. China

E-mail: drzyzeng@126.com

*Contributed equally

Key words: cardiac valve damage, rheumatic heart disease, miR-155-5p, signal transducer and activator of transcription 3, sphingosine-1-phosphate receptor 1, suppressor of cytokine signaling 1 showed that miR-155-5p directly targeted S1PR1 and SOCS1. Inhibition of valvular miR-155-5p through AAV pretreatment increased S1PR1 expression and inhibited activation of the SOCS1/STAT3 signal pathway as a result of attenuated valvular inflammation and fibrosis as well as a decrease in IL-6 and IL-17 in the valves and serum. These results suggest that inhibition of miR-155-5p can reduce RHD-induced valvular damage via the S1PR1, SOCS1/STAT3 and IL-6/STAT3 signaling pathways.

\section{Introduction}

The global burden of rheumatic heart disease (RHD) has decreased in recent decades, but the prevalence and mortality in low- and middle-income countries remain high. RHD affects $>30$ million people each year and results in $>300,000$ deaths annually (1). The pathogenesis of RHD results from streptococcus-induced autoimmunity, but the specific pathophysiology and molecular mechanisms remain unknown $(2,3)$.

MicroRNAs (miRNAs/miRs) are small noncoding RNAs that regulate posttranscriptional gene expression by binding to 3' untranslated regions (3'UTRs). The roles played by miRNAs in regulating inflammation, immunity and fibrosis have been confirmed, but the role of miR-155-5p in RHD remains unclear. The tyrosine phosphorylation of signal transducer and activator of transcription 3 (STAT3) is associated with malignancy (4) and rheumatoid arthritis (5-7). The phosphorylation of STAT3 is negatively regulated by suppressor of cytokine signaling 1 (SOCS1) in atherogenesis (8) and rheumatoid arthritis (9). Sphingosine-1-phosphate receptor 1 (S1PR1), a sphingosine-1-phosphate (S1P) receptor, has been shown to be a factor in inflammation, autoimmunity and anti-fibrotic function. The authors previously reported low expression of S1PR1 and activation of STAT3 phosphorylation in the RHD rat model (10), but the specific mechanisms of these findings remain unclear.

The purpose of the current study was to determine the roles of miR-155/S1PR1 and the miR-155/SOCS1/STAT3 signaling pathways in RHD-induced valvular damage. A rat model of RHD was established by injecting formaldehyde-inactivated Group A streptococci and complete Freund's adjuvant, and the expression of miR-155-5p in the heart was inhibited by injecting recombinant adeno-associated virus. After inhibition of miR-155-5p, the valvar damage 
was detected. The relationships between miR-155-5p, and S1PR1 and SOCS1 were investigated, and the expression of S1PR1, SOCS1, STAT3, interleukin (IL)-6 and IL-17 was detected. The findings suggested that the S1PR1 and SOCS1 genes are targets of miR-155-5p, that the miR-155/S1PR1 and miR-155/SOCS1/STAT3 pathways are major components of RHD-induced valvular damage, and that the inhibition of miR-155 could alleviate the progression of valvular damage.

\section{Materials and methods}

Animals. An experimental RHD animal model was established as described previously $(10,11)$. Female Lewis rats were purchased at 8 weeks of age (150-180 g) from Beijing Vital River Animal Technology, Co., Ltd. The acclimation period for the rats was 5 days. The rats were bred in a specific pathogen-free animal laboratory at the Center of Animal Experiments of Guangxi Medical University. The rats were housed at $23 \pm 2{ }^{\circ} \mathrm{C}$ with a 12 -h light/dark cycle and were allowed unrestricted cage activity and unlimited access to water and standard chow. All animal experimental procedures were performed according to the ethical guidelines for the care and use of laboratory animals and were approved by the Medical Ethics Committee of the First Affiliated Hospital of Guangxi Medical University (grant no. 2019-KY-E-009).

Antigen preparation. Group A streptococci(GAS, ATCC19615; American Type Culture Collection) were cultured in brain heart infusion fluid medium (Guangdong Huankai Microbial Sci. \& Tech. Co., Ltd.) at $37^{\circ} \mathrm{C}$ for $24 \mathrm{~h}$, collected and then washed with normal saline (NS). After harvesting, the GAS were inactivated by $10 \%$ neutral formalin for $12 \mathrm{~h}$. The formaldehyde-inactivated GAS were washed and resuspended in sterile NS adjusted to a concentration of $4.0 \times 10^{11} \mathrm{CFU} / \mathrm{ml}$. Suspensions were fully emulsified using sonic breaking (Sonics \& Materials, Inc.) to create antigen A. Antigen B was prepared using a GAS suspension with an equal volume of complete Freund's adjuvant (Sigma-Aldrich, Merck KGaA).

Immunization of Lewis rats. A total of 20, 8-week-old female Lewis rats were randomly divided into two groups: A control group and an RHD group. Briefly, the RHD rat model was established by injecting formaldehyde-inactivated GAS and complete Freund's adjuvant. Patients with RHD can develop carditis, valve damage, fibrosis and calcification (12). According to this, rats with valvular damage and fibrosis were considered as successfully established models (13). More specifically, rats in the RHD group were injected into the hind foot pad with $0.2 \mathrm{ml}$ antigen $\mathrm{B}$ on day 0 . After one week of rest, the rats were injected subcutaneously in the abdomen with $0.5 \mathrm{ml}$ antigen $\mathrm{B}$ on days 7, 14, 21 and 28 , followed by antigen A on days 35, 42, 49 and 56. The rats in the control group were injected with NS following the same protocol. A total of $1.5 \mathrm{ml}$ blood was collected via tail veins without extra anaesthesia on day 63. All the rats were sacrificed by intraperitoneal injection of pentobarbital sodium $(150 \mathrm{mg} / \mathrm{kg})$ on day 63; lack of heartbeat and breathing for $>5$ min were considered to indicate animal death. Body weight loss of $>15 \%$ with a decreased ability to consume food and water was used as humane endpoint.
Histochemistry. Samples were taken from valves in every group and fixed in $4 \%$ paraformaldehyde for $24 \mathrm{~h}$ at $4^{\circ} \mathrm{C}$. Then, the tissues were decalcified and embedded in paraffin blocks. The blocks were sliced at $5 \mu \mathrm{m}$ for hematoxylin and eosin (H\&E) staining and Sirius red staining. For H\&E staining, the sections were stained with hematoxylin for 4-10 min at room temperature and then eosin for 0.5-2 $\mathrm{min}$ at room temperature. The images were captured using a BX43 light microscope (Olympus Corporation). For Sirius red staining, sections were stained with Sirius red solution for $1 \mathrm{~h}$ at room temperature. The images were captured using a BX43 confocal microscope (magnification, x100; Olympus Corporation).

Immunohistochemistry. The valve tissues stained for S1PR1 (1:80; cat. no. ab77076; Abcam), STAT3 (1:75; cat. no. ab69153; Abcam), phosphorylated (p-)STAT3 (1:70; cat. no. ab76315; Abcam), IL-6 (1:65; cat. no. ab9324; Abcam) and IL-17 (1:90; cat. no. ab214588; Abcam) were analyzed by immunohistochemistry. Sections $(5 \mu \mathrm{m})$ of formalin-fixed paraffin-embedded tissue specimens were blocked in 5\% bovine serum albumin (BSA; Beijing Solarbio Science \& Technology Co., Ltd.) solution for $1 \mathrm{~h}$ at room temperature after deparaffinization and rehydration. The sections were added to hydrogen peroxide for $20 \mathrm{~min}$ at $25^{\circ} \mathrm{C}$ to eliminate endogenous peroxidase and washed using phosphate-buffered saline. Sections were incubated for $12 \mathrm{~h}$ at $4^{\circ} \mathrm{C}$ with the primary antibodies mentioned above and then incubated with anti-rabbit horseradish peroxidase (HRP)-conjugated (1:10; cat. no. PV-6001; OriGene Technologies, Inc.) or anti-mouse HRP-conjugated (1:10; cat. no. PV-6002; OriGene Technologies, Inc.) secondary antibodies for $30 \mathrm{~min}$ at room temperature. Diaminobenzidine (DAB) was used as an enhancement factor for color development. After restaining with hematoxylin and dehydrating, the images were captured using a BX43 light microscope (Olympus Corporation). Brownish yellow staining detected by microscopy indicated positive expression. Quantitative assessments were performed based on the methods described by Friedrichs et al (14). Briefly, five high-power field (magnification, x400) images were randomly selected and the immunoreactive score and positive cell percentage were used to describe the expression levels. Each test was performed in triplicate.

$R T-q P C R$. Total RNA was extracted from valves and serum exosomes using the TRIzol ${ }^{\circledR}$ reagent (Invitrogen; Thermo Fisher Scientific, Inc.) according to the manufacturer's protocol. The RNA concentration was measured using a NanoDrop ${ }^{\mathrm{TM}}$ 2000 spectrophotometer (NanoDrop Technologies; Thermo Fisher Scientific, Inc.). A total of $0.5 \mu \mathrm{g}$ of total RNA was reverse transcribed into cDNA using the PrimeScript RT Reagent kit (Takara Bio, Inc.) for mRNA. The reverse transcription conditions were as follows: $37^{\circ} \mathrm{C}$ for $15 \mathrm{~min}$ and $85^{\circ} \mathrm{C}$ for $5 \mathrm{sec}$. A total of $1 \mu \mathrm{g}$ of total RNA or serum exosome RNA was reverse-transcribed using the Mir-X ${ }^{\mathrm{TM}}$ miRNA First-Strand Synthesis kit (Takara Bio, Inc.). The reverse transcription conditions were as follows: $37^{\circ} \mathrm{C}$ for $60 \mathrm{~min}$ and $85^{\circ} \mathrm{C}$ for $5 \mathrm{~min}$. RT-qPCR was performed using TB Green Premix Ex Taq II (Takara Bio, Inc.) in a StepOne system (Applied Biosystems; Thermo Fisher Scientific, Inc.) with the 
Table I. Sequences of primers used in reverse transcription-quantitative PCR.

\begin{tabular}{ll}
\hline Gene & \multicolumn{1}{c}{ Primer sequence (5'-3') } \\
\hline miR-155-5p & Forward: ACGCGTTAATGCTAATTGTGATAGGGGT \\
U6 & Forward: GGAACGATACAGAGAAGATTAGC \\
STAT3 & Reverse: TGGAACGCTTCACGAATTTGCG \\
& Forward: TTTGAGACAGAGGTGTACCACCAAG \\
S1PR1 & Reverse: ACCACAGGATTGATGCCCAAG \\
SOCS1 & Forward: GCTTCATCACTCACTACCCTAGCA \\
Col3a1 & Reverse: TTCTCCCTTCCCTCCCTCTC \\
FSP1 & Forward: CACGCACTTCCGCACATTCC \\
& Reverse: TCCAGCAGCTCGAAGAGGGA \\
& Forward: ACTTCTGGTCCTCCTGGTCTGC \\
& Reverse: CGCCTGGCTCACCCTTTTCAC \\
& Forward: TGGGGAGAAGGACAGACGAAGC \\
& Reverse: TGGCAATGCAGGACAGGAAGAC \\
& Forward: GGAGATTACTGCCCTGGCTCCTA \\
& Reverse: GACTCATCGTACTCCTGCTTGCTG
\end{tabular}

STAT3, signal transducer and activator of transcription 3; S1PR1, sphingosine-1-phosphate receptor 1; SOCS1, suppressor of cytokine signaling 1; Col3a1, collagen type III $\alpha 1$ chain; FSP1, fibroblast-specific protein 1; miR, microRNA.

following thermocycling conditions: $95^{\circ} \mathrm{C}$ for $30 \mathrm{~min}$, followed by 40 cycles at $95^{\circ} \mathrm{C}$ for $5 \mathrm{sec}$ and $60^{\circ} \mathrm{C}$ for $30 \mathrm{sec}$. The primers used are listed in Table I. The mRNA and miRNA expression levels were normalized to $\beta$-actin and U6 expression, respectively, using the $2^{-\Delta \Delta \mathrm{Cq}}$ method (15). Samples were measured in three independent replicates.

Western blotting. Samples of valve tissues were treated with RIPA lysis buffer (Sangon Biotech Co., Ltd.) and were centrifuged at $12,000 \mathrm{x} \mathrm{g}$ at $4^{\circ} \mathrm{C}$ for $15 \mathrm{~min}$ to obtain the supernatant, according to the manufacturer's protocol. The protein concentration was subsequently quantified with a bicinchoninic acid protein assay (Sangon Biotech Co., Ltd.). Protein lysates were mixed with 4X loading buffer (Beijing Solarbio Science \& Technology Co., Ltd.) and boiled at $95^{\circ} \mathrm{C}$ for $5 \mathrm{~min}$. Equal amounts of protein $(20 \mu \mathrm{g})$ were separated by $10 \%$ SDS-PAGE at $60 \mathrm{~V}$ for $30 \mathrm{~min}$ and $120 \mathrm{~V}$ for $70 \mathrm{~min}$ by a blotting system (Bio-Rad Laboratories, Inc.). The separated protein was electrotransferred to $0.22 \mu \mathrm{m}$ PVDF membranes (EMD Millipore) at a constant $300 \mathrm{~mA}$ for $90 \mathrm{~min}$. After electrotransfer, the membranes were blocked with $3 \%$ BSA blocking solution (Sangon Biotech Co., Ltd.) for $1 \mathrm{~h}$ at room temperature and then probed with the following antibodies for $12 \mathrm{~h}$ at $4^{\circ} \mathrm{C}$ : S1PR1 (1:3,000; cat. no. ab125074; Abcam), SOCS1 (1:1,000; cat. no. 3950; Cell Signaling Technology, Inc.), STAT3 (1:1,000; cat. no. ab68153; Abcam), p-STAT3 (1:1,000; cat. no. 9145; Cell Signaling Technology, Inc.) and $\beta$-tubulin (1:3,000; cat. no. 10068-1-AP; ProteinTech Group, Inc.). The membranes were incubated with HRP-conjugated secondary antibody (10,000; cat. no. ab6721; Abcam) for $1 \mathrm{~h}$ at room temperature. All samples were measured in triplicate. The expression of S1PR1, STAT3 and p-STAT3 was quantified by normalizing to $\beta$-tubulin using ImageJ software $(1.51 \mathrm{j}$, National Institute of Health).
Isolation and identification of exosomes. Exosomes were isolated from serum using the ExoQuick ULTRA Isolation kit (System Biosciences) according to the manufacturer's protocol. Western blotting was used to detect the exosome-specific membrane markers cluster of differentiation (CD)9 (cat. no. ab92726; Abcam; 1:1,000) and CD63 (cat. no. ab108950; Abcam; 1:1,000). Nanoparticle tracking analysis (NTA) was used to measure both the size and concentration of exosomes with a ZetaView PMX120 system (Particle Metrix). Transmission electron microscopy (TEM; Tecnai G2 spirit, FEI) was used to observe the morphology of exosomes at $80 \mathrm{kV}$ after staining with $2 \%$ uranyl acetate for $1 \mathrm{~min}$ at room temperature. All experiments were performed in triplicate.

Dual luciferase assay. The potential relationships between miR-155-5p and SOCS1 and S1PR1 were predicted by TargetScan 7.2 (http://www.targetscan.org). The 293T cells were obtained from the Cell Bank of Type Culture Collection of Chinese Academy of Sciences. The cells were cultured in Dulbecco's modified Eagle's medium (Gibco; Thermo Fisher Scientific, Inc.) supplemented with $10 \%$ fetal bovine serum (Gibco; Thermo Fisher Scientific, Inc.) in an incubator at $37^{\circ} \mathrm{C}$ and $5 \% \mathrm{CO}_{2}$. Both the wild-type (WT) and the mutant-type (MUT) 3'-UTR of S1PR1 and SOCS1 mRNA were amplified by PCR and inserted into psiCHECK-2 dual-luciferase reporter plasmids downstream of the Renilla luciferase gene (Promega Corporation). The $0.16 \mu \mathrm{g}$ S1PR1 WT 3'-UTR, S1PR1 MUT 3'-UTR or negative control (NC) 3'-UTR plasmids were cotransfected with 5 pmol miR-155-5p mimics (5'-UUAAUGCUAAUUGUGAUAGGG GU-3') or miR-NC mimics (5'-UUCUCCGAACGUGUCACG UdTdT-3') into 293T cells using X-tremeGENE ${ }^{\text {TM }}$ HP DNA Transfection Reagent (Roche Diagnostics). The $0.16 \mu \mathrm{g}$ SOCS1 WT 3'-UTR or SOCS1 MUT 3'-UTR were cotransfected with 
A
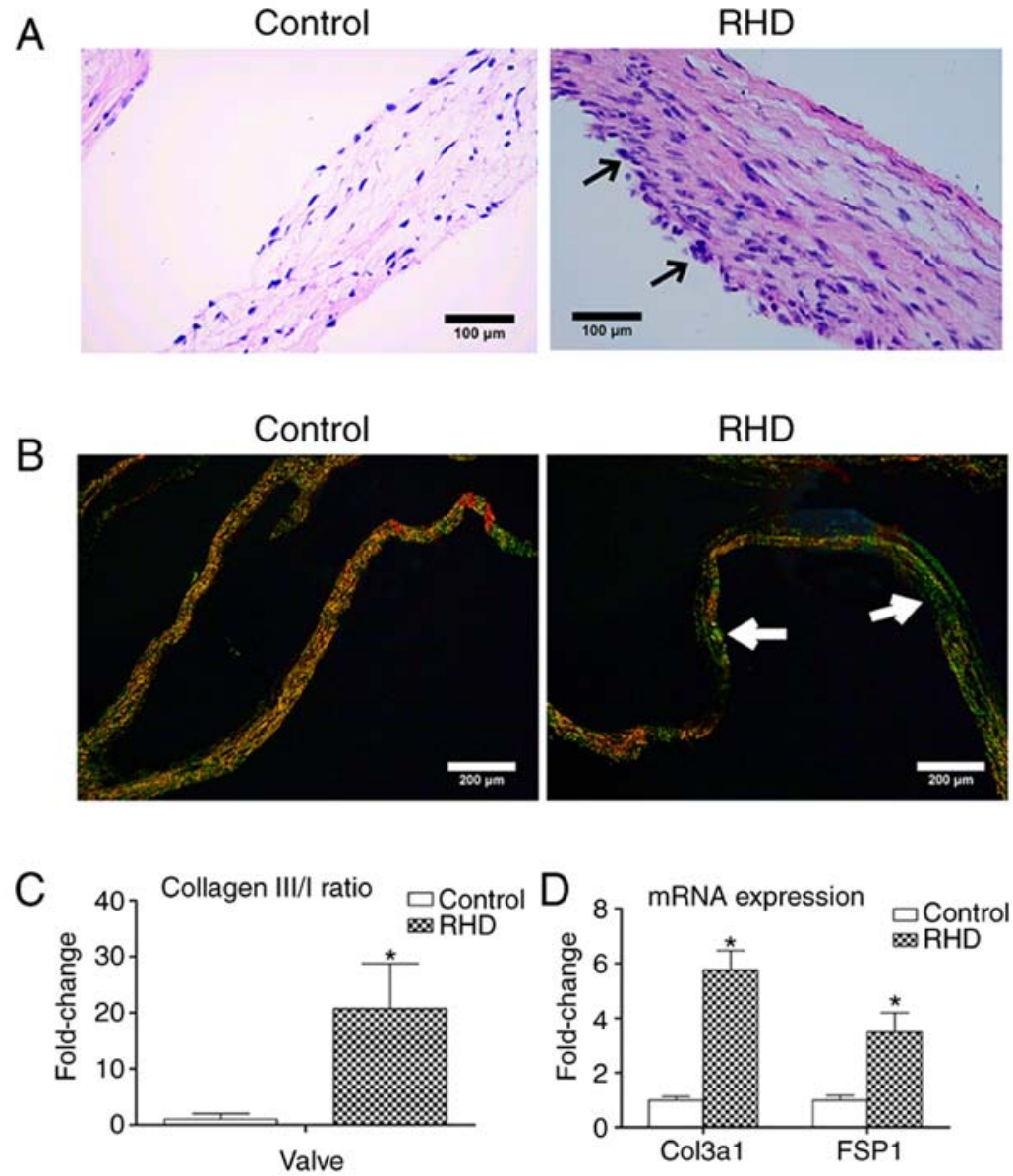

RHD

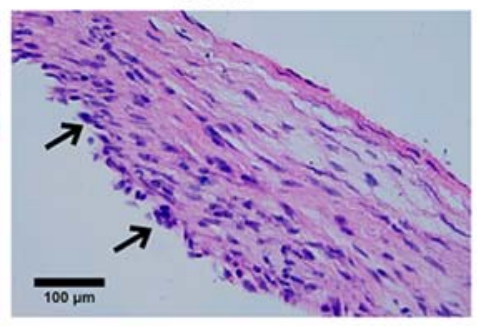

RHD

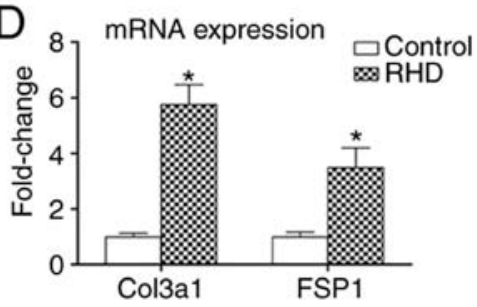

Figure 1. H\&E, Sirius red staining and fibrosis molecular markers of valve tissues. (A) H\&E staining; RHD-induced valvular damage was observed in RHD group; magnification, $\mathrm{x} 400$; scale bar: $100 \mu \mathrm{m}$; the arrows represent inflammatory cells and inflammatory exudate (B). Sirius red staining, RHD-induced fibrosis was observed in RHD group; magnification, x100; scale bar: $200 \mu \mathrm{m}$; the arrows represent COL3 (green fibers with weak birefringence). (C) The COL3/1 ratio of valves in the RHD group was higher than that in the control group. (D) Relative expression of Col3a1 and FSP1 in that RHD group were increased compared with those in the control group. Data are shown as the mean \pm standard deviation; ${ }^{*} \mathrm{P}<0.05$ vs. the control group. H\&E, hematoxylin and eosin staining; COL3, collagen fiber type 3; COL1, collagen fiber type 1; Col3a1, collagen type III $\alpha 1$ chain; FSP1, fibroblast-specific protein 1; RHD, rheumatic heart disease.

5 pmol miR-155-5p mimics or miR-NC mimics into 293T cells. After $48 \mathrm{~h}$, the luciferase activities were tested using a Dual-Luciferase Reporter Assay system (Promega Corporation), Renilla luciferase activity was normalized to firefly luciferase activity; experiments were performed in triplicate.

In vivo gene therapy. Recombinant adeno-associated virus (serotype 9) vectors carrying a rat miR-155-5p (MIMAT0030409) inhibition sequence with a c-TNT promoter (AAV-miR155-inhibitor; Han Biomedical, Inc.) were used. An AAV-control was used as a negative control. A total of 24 female Lewis rats were randomly divided into four groups: Control group ( $\mathrm{n}=6)$, RHD group ( $\mathrm{n}=6$ ), RHD+AAV-control group (AAV-control; $n=6$ ) and RHD+AAV-miR155-inhibitor group (AAV-miR155-inhibitor; $\mathrm{n}=6$ ). Each rat in the AAV-control and AAV-miR155-inhibitor group was given a single injection of $2.5 \times 10^{11}$ viral genome particles (AAV-control or AAVmiR155-inhibitor, diluted in $200 \mu 1$ normal saline) via the tail vein. A total of 3 weeks after the injection, RHD models were established in the RHD group, the AAV-control group and the AAV-miR155-inhibitor group following the procedure mentioned above.
ELISA. To study the cytokine levels in the serum, rat IL-6 and IL-17 were measured using ELISA kits according to the manufacturer's protocol (cat. nos. E04640r and E07451r; Cusabio). All samples were measured in triplicate.

Statistical analysis. All data are expressed as the mean \pm standard deviation for at least three separate experiments. Statistical analysis was performed using SPSS software 16.0 (SPSS, Inc.). A Student's t-test was used to analyze the differences between two groups. One-way analysis of variance with Tukey's post hoc test was used to analyze the differences among four groups. $\mathrm{P}<0.05$ was considered to indicate a statistically significant difference.

\section{Results}

Pathological examination of the RHD model. H\&E staining showed that the rats in the RHD group presented with acute valvulitis. Diffuse infiltration of inflammatory cells, thickened valves, inflammatory exudate and fibrosis were observed under microscopy. None of these changes were found in the control group (Fig. 1A). 
A

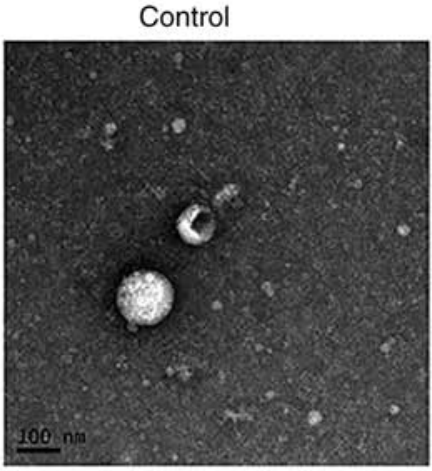

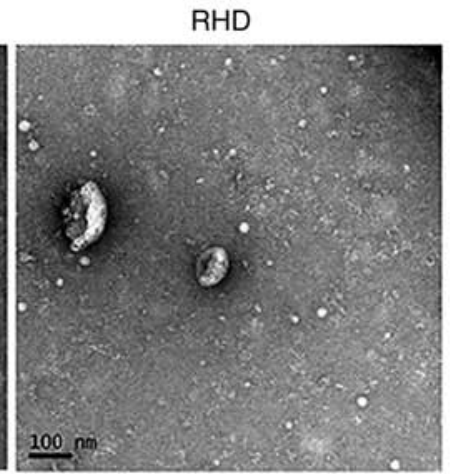

B

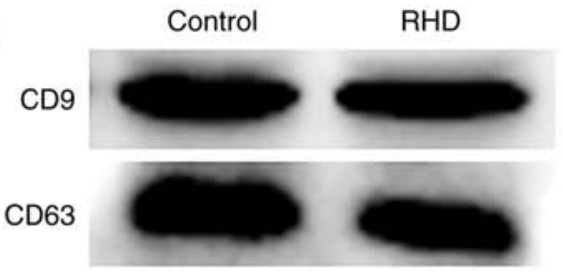

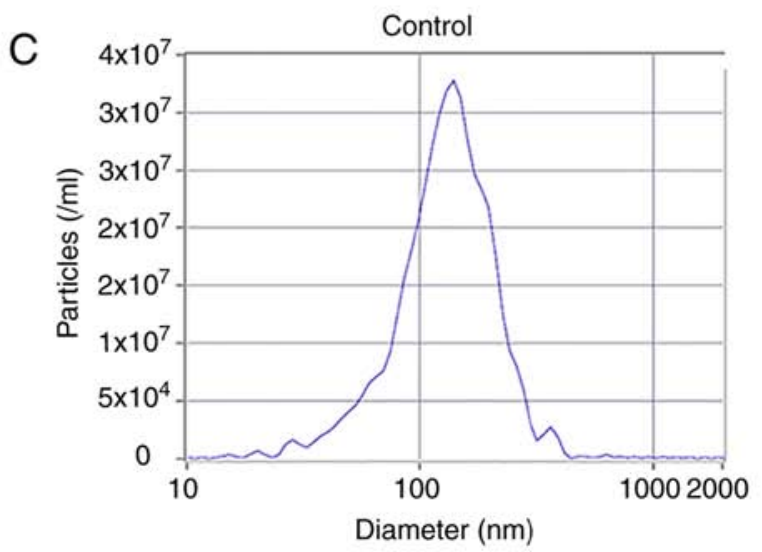

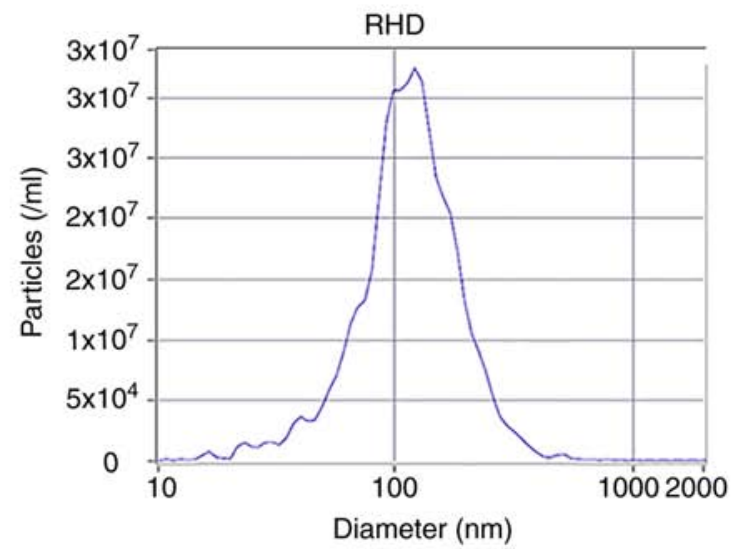

Figure 2. Identification of serum exosomes. (A) Transmission electron micrograph of exosomes, their morphology was round vesicles with double membranes; scale bar: $100 \mathrm{~nm}$. (B) Western blot analysis of CD9 and CD63; (C) The size and concentration of exosomes detected by the nanoparticle tracking analysis system, the peak diameters were $117.2 \mathrm{~nm}$ (RHD group) and $137.1 \mathrm{~nm}$ (control group), and the concentrations were $3.2 \times 10^{7} / \mathrm{ml}$ (RHD group) and $3.3 \times 10^{7} / \mathrm{ml}^{2}$ (control group). CD, cluster of differentiation; RHD, rheumatic heart disease.

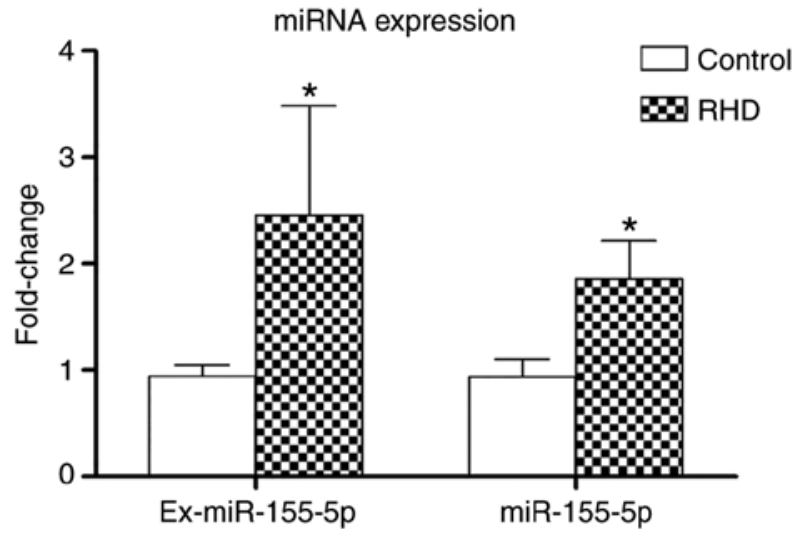

Figure 3. Reverse transcription-quantitative PCR analysis of miR-155-5p in serum exosomes and valve tissues. The relative expression of miR-155-5p in serum exosomes and valve tissues in the RHD group was higher than that in the control group. Data are shown as the mean \pm standard deviation; ${ }^{*} \mathrm{P}<0.05$ vs. the control group. miR, microRNA; RHD, rheumatic heart disease; $\mathrm{miR} / \mathrm{miRNA}$, microRNA.

The types of collagen fibers can be distinguished by Sirius red staining with polarized light. Collagen fiber type 1 (COL1) appeared as close-packed yellow and red fibers with obvious birefringence, and collagen fiber type 3 (COL3) appeared as loosely arranged green fibers with weak birefringence. The relative increase in COL3 and decrease in COL1 were calculated by the COL3/COL1 (COL3/1) ratio. The COL3/1 ratio of valves in the RHD group was significantly 20.32-fold higher than that in the control group $(\mathrm{P}<0.05$; Fig. $1 \mathrm{~B}$ and $\mathrm{C})$. A previous study indicated that COL1 is the major type of collagen in valves without fibrosis (16). With the progression of fibrosis, the proportion of COL3 increases gradually. The significant increase in the COL3/1 ratio therefore confirmed the initiation of fibrosis in the valves and myocardium.

The mRNA expression levels of collagen type III $\alpha 1$ chain (Col3a1) and fibroblast-specific protein 1 (FSP1) were used as fibrosis molecular markers. The mRNA levels of Col3a1 and FSP1 in the RHD group were significantly increased compared with the control group $(\mathrm{P}<0.05$; Fig. 1D).

Identification of serum exosomes. Exosomes were isolated from the serum and observed using TEM. Their morphology was round vesicles with double membranes (Fig. 2A). Specific membrane markers CD9 and CD63 were detected in the exosomes by western blotting (Fig. 2B). The NTA results demonstrated that the peak diameters were $117.2 \mathrm{~nm}$ (RHD group) and $137.1 \mathrm{~nm}$ (control group) and the concentrations were $3.2 \times 10^{7} / \mathrm{ml}$ (RHD group) and $3.3 \times 10^{7} / \mathrm{ml}$ (control group; Fig. 2C).

miR-155-5p is upregulated in serum exosomes and valve tissues in the RHD model. RT-qPCR results showed that the amount of miR-155-5p extracted from the serum exosomes (ex-miR155-5p) and valves of the RHD group were 
A

\begin{tabular}{|l|lcl|}
\hline & \multicolumn{3}{|c|}{$\begin{array}{c}\text { Predicted consequential pairing of target region (top) } \\
\text { and miRNA (bottom) }\end{array}$} \\
\hline Position 1087-1093 of S1PR1 3' UTR & 5, & $\ldots$ CUUUGUACCCAAAAAAGCAUUAC. . & $\mid$ | | | | | | \\
rno-miR-155-5p & 3, & UGGGGAUAGUGUUAAUCGUAAUU &
\end{tabular}

B

\begin{tabular}{|l|lcl} 
& \multicolumn{2}{|c}{$\begin{array}{c}\text { Predicted consequential pairing of target region (top) and } \\
\text { miRNA (bottom) }\end{array}$} \\
\hline Position 21-28 of SOCS1 3' UTR & 5, & $\ldots$ UGCCGCCGUGCCCGCAGCAUUAA. . . & |||||||| \\
rno-miR-155-5p & 3, & UGGGGAUAGUGUUAAUCGUAAUU &
\end{tabular}

C

$\square$ S1PR1 WT3' UTR+miR-NC mimics

$\otimes$ S1PR1 WT3' UTR+miR-155-5p mimics

$Z \triangle N C 3^{\prime}$ UTR + miR-155-5p mimics

용 S1PR1 MUT3' UTR+miR-155-5p mimics

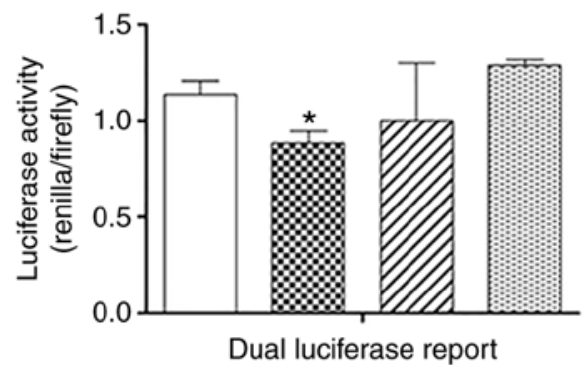

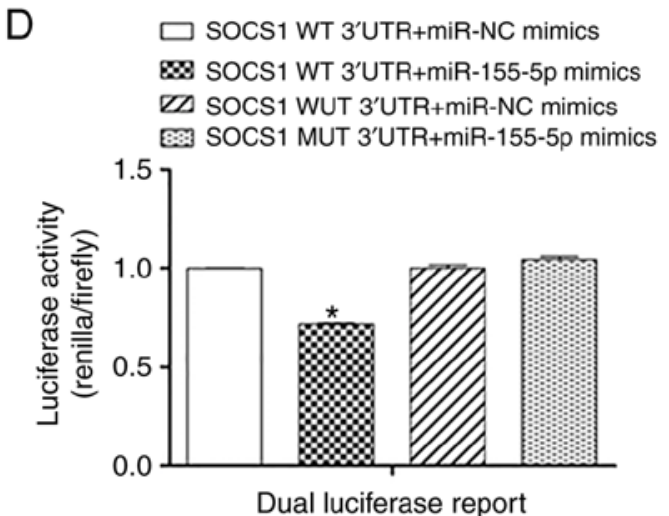

Figure 4. Dual luciferase assay. (A) Prediction of the relationship between miR-155-5p and S1PR1, the result predicted that S1PR1 could be a potential target of miR-155-5p. (B) Prediction of the relationship between miR-155-5p and SOCS1, the result predicted that SOCS1 could be a potential target of miR-155-5p. (C) Dual luciferase assay; miR-155-5p directly targets S1PR1. (D) Dual luciferase assay; miR-155-5p directly targets SOCS1. Data are shown as the mean \pm standard deviation; ${ }^{*} \mathrm{P}<0.05$ vs. the first group. miR/miRNA, microRNA; S1PR1, sphingosine-1-phosphate receptor 1; SOCS1, suppressor of cytokine signaling 1 ; UTR, untranslated region.

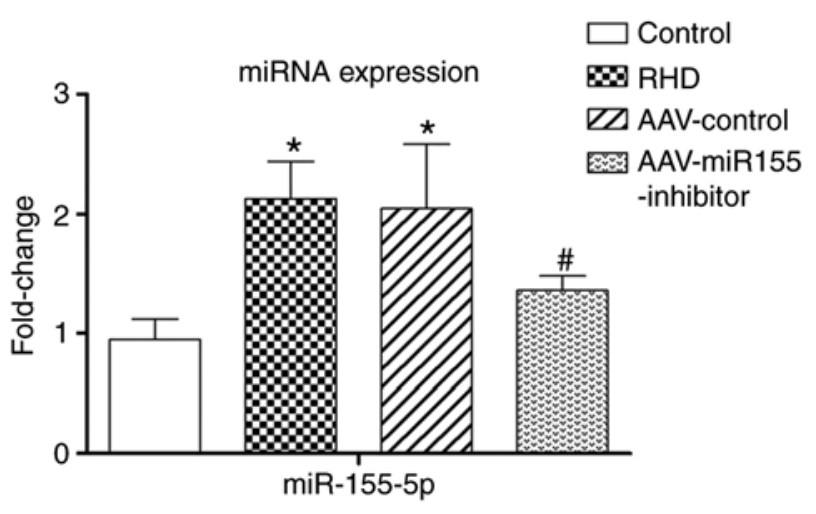

Figure 5. Reverse transcription-quantitative PCR analysis of miR-155-5p in the four groups. The relative expression of miR-155-5p in the AAV-miR155-inhibitor group was lower than that in the RHD group. Data are shown as the mean \pm standard deviation; ${ }^{*} \mathrm{P}<0.05$ vs. the control group. ${ }^{\#} \mathrm{P}<0.05$ vs. the RHD group. miR/miRNA, microRNA; RHD, rheumatic heart disease.

significantly 2.61 -fold and 1.99 -fold higher than in the control group, respectively $(\mathrm{P}<0.05$; Fig. 3$)$. These results demonstrate a potential relationship between miR-155-5p and RHD.

miR-155-5p directly targets S1PR1. The TargetScan results predicted that the S1PR1 gene could be a potential target of miR-155-5p (Fig. 4A). A dual luciferase assay was established to verify this prediction. When the miR-155-5p mimics were cotransfected with S1PR1 WT 3' UTR, the relative luciferase activity (Renilla/firefly) was significantly decreased compared with S1PR1 WT 3' UTR cotransfected with miR-NC mimics $(\mathrm{P}<0.05)$. The same effect did not occur when miR-155-5p was overexpressed in the S1PR1 MUT 3' UTR (Fig. 4C).

miR-155-5p directly targets SOCSI. The TargetScan results predicted that the SOCS1 gene could be a potential target of miR-155-5p (Fig. 4B). A dual luciferase assay was established to verify this prediction. When the miR-155-5p mimics were cotransfected with SOCS1 WT 3' UTR, the relative luciferase activity (Renilla/firefly) was significantly decreased compared with when SOCS1 WT 3' UTR was cotransfected with miR-NC mimics $(\mathrm{P}<0.05)$. The same effect did not occur when miR-155-5p or miR-NC were cotransfected with the SOCS1 MUT 3' UTR (Fig. 4D).

AAV-miR155-inhibitor pretreatment attenuates valvular damage. To determine whether miR-155-5p participates in RHD-induced valvular damage, the cardiac-specific AAV-miR155-inhibitor was injected via the rat tail vein. RT-qPCR results showed that the amount of miR-155-5p in 
A

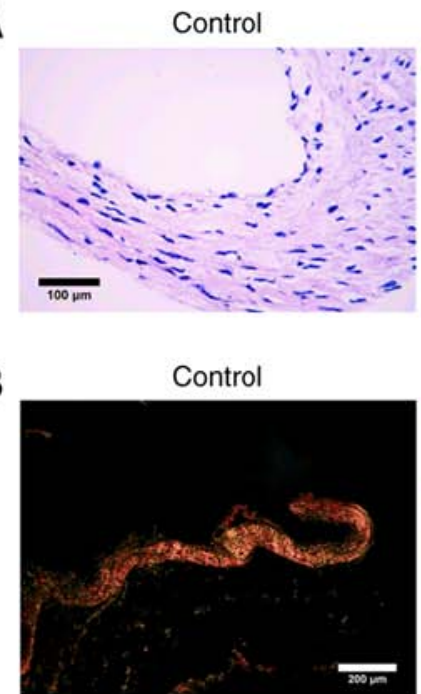

RHD

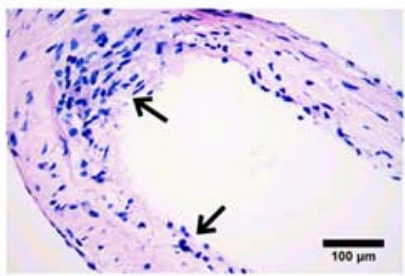

RHD

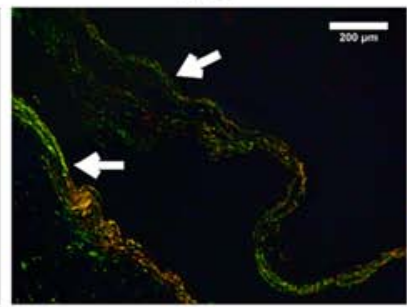

AAV-control
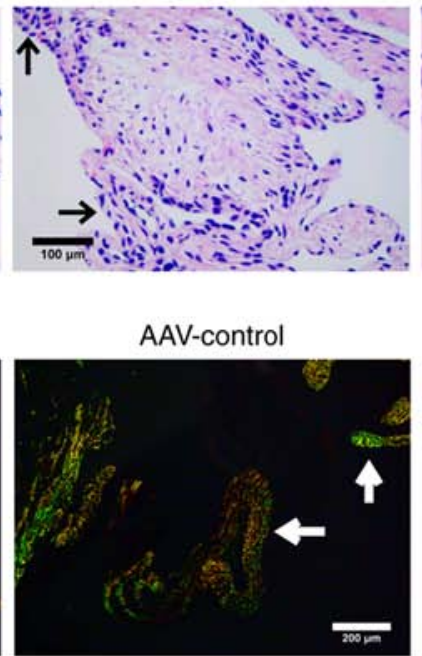

AAV-miR155-inhibitor
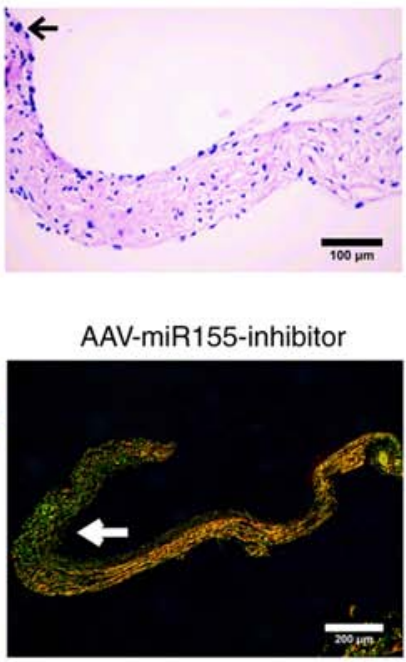

C

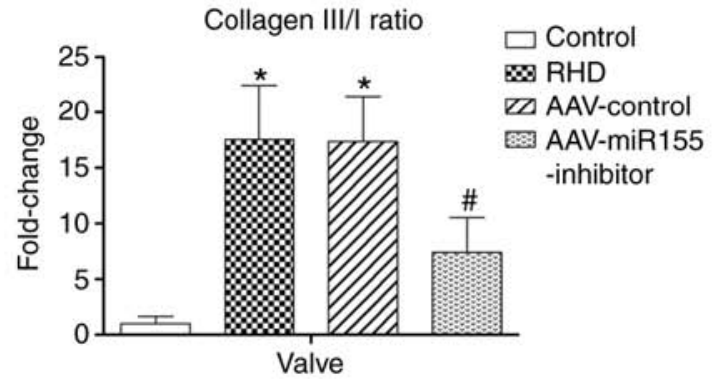

D

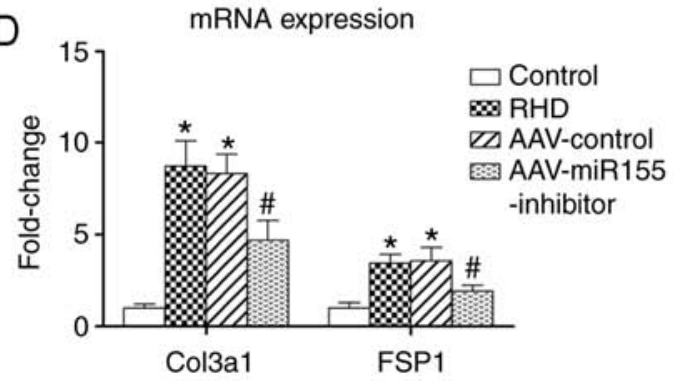

Figure 6. H\&E, Sirius red staining and fibrosis molecular markers of four groups. (A) H\&E, reduced inflammatory cell infiltration and inflammatory exudate were also observed after AAV-injection; magnification, x400; scale bar: $100 \mu \mathrm{m}$; the arrows represent inflammatory cells and inflammatory exudate. (B) Sirius red staining, less fibrosis was observed after AAV-injection; magnification, x100; scale bar: $200 \mu$ m, the arrows represent COL3 (green fibers with weak birefringence). (C) COL3/COL1 ratio in AAV-miR155-inhibitor group was lower than that in RHD group. (D) The relative expression of Col3a1 and FSP1 in the AAV-miR155-inhibitor group was lower than that in the RHD group. Data are shown as the mean \pm standard deviation; ${ }^{*} \mathrm{P}<0.05$ vs. the control group. ${ }^{\#} \mathrm{P}<0.05$ vs. the RHD group. H\&E, hematoxylin and eosin staining; COL3, collagen fiber type 3; COL1, collagen fiber type 1; Col3a1, collagen type III $\alpha 1$ chain; FSP1, fibroblast-specific protein 1; RHD, rheumatic heart disease; miR, microRNA.

the AAV-miR155-inhibitor group was significantly 1.56-fold lower than in the RHD group after a 9-week modeling procedure $(\mathrm{P}<0.05$; Fig. 5). Reduced inflammatory cell infiltration and inflammatory exudate were also observed (Fig. 6A). Sirius red staining results showed that both valves in the AAV-miR155-inhibitor group had less fibrosis compared with the RHD group (Fig. 6B). The COL3/1 ratio in the AAV-miR155-inhibitor group was significantly 2.36-fold lower than that in the RHD group $(\mathrm{P}<0.05$; Fig. $6 \mathrm{C})$. The mRNA expression of Col3al and FSP1 in the AAV-miR155-inhibitor group was significantly decreased compared with the RHD group $(\mathrm{P}<0.05$; Fig. 6C). Thus, these findings indicate that miR-155-5p is a negative regulatory factor of RHD-induced valvular damage.

mRNA levels of S1PR1, SOCS1 and STAT3. The mRNA levels of S1PR1 and SOCS1 in the RHD group and the AAV-control group were significantly decreased compared with in the control group $(\mathrm{P}<0.05)$, and there was no significant difference between the two groups. The mRNA levels of S1PR1 and SOCS1 in the AAV-miR155-inhibitor group were significantly increased compared with those in the RHD group $(\mathrm{P}<0.05)$. There were no differences between the four groups in the mRNA level of STAT3 (Fig. 6A).
Protein levels of S1PR1, SOCS1, STAT3 and p-STAT3. Western blotting and immunohistochemistry showed significant downregulation of S1PR1 and SOCS1 in the RHD and AAV-control groups compared with the control group $(\mathrm{P}<0.05)$, and there was no significant difference between the RHD and AAV-control groups. The protein levels of p-STAT3, p-STAT3/t-STAT3 protein ratio, $\mathrm{p}$-STAT3/t-STAT3 ISH ratio and p-STAT3/t-STAT3 positive cell\% ratio in the RHD and AAV-control groups were significantly increased compared with those in the control group $(\mathrm{P}<0.05)$, and there was no significant difference between the RHD and AAV-control groups. The protein levels of STAT3 in the four groups were similar. Nevertheless, the AAV-miR155-inhibitor pretreatment significantly enhanced the S1PR1 and SOCS1 protein levels compared with the RHD group $(\mathrm{P}<0.05)$ and significantly reduced the $\mathrm{p}$-STAT3 protein expression, $\mathrm{p}-\mathrm{STAT} 3 / \mathrm{t}-\mathrm{STAT} 3$ protein ratio, $\mathrm{p}-\mathrm{STAT} 3 / \mathrm{t}-\mathrm{STAT} 3 \mathrm{ISH}$ ratio and $\mathrm{p}-\mathrm{STAT} 3 /$ t-STAT3 positive cell\% ratio. $(\mathrm{P}<0.05$; Figs. $7 \mathrm{~B}-\mathrm{D}$, and $8 \mathrm{~A}-\mathrm{E})$.

$A A V$-miR155-inhibitor pretreatment attenuates the expression of IL- 6 and IL-17. Immunohistochemistry and ELISA showed that the expression levels of IL-6 and IL-17 in the RHD and AAV-control groups were significantly increase compared with in the control group $(\mathrm{P}<0.05)$. The AAV-miR155-inhibitor 
A

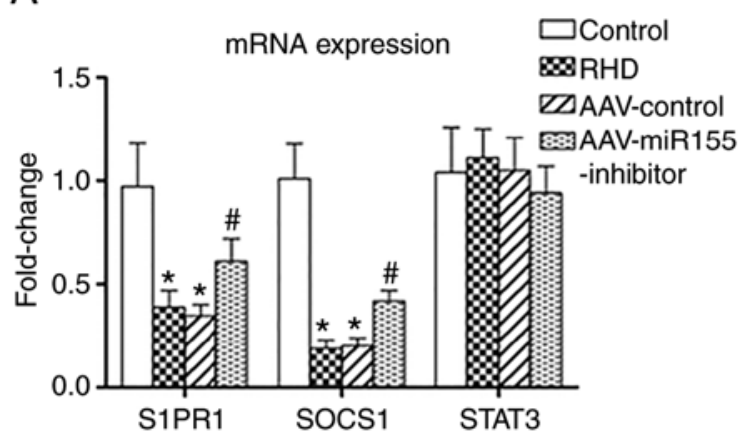

C

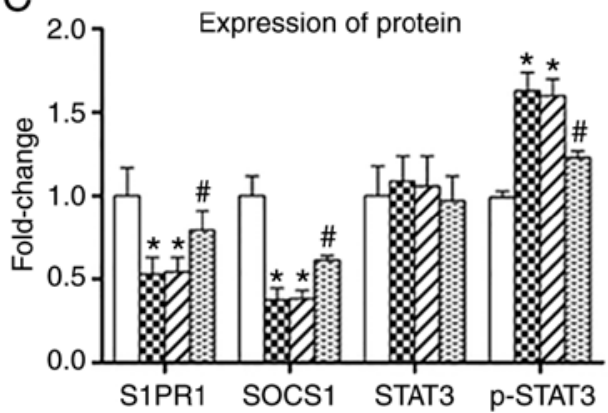

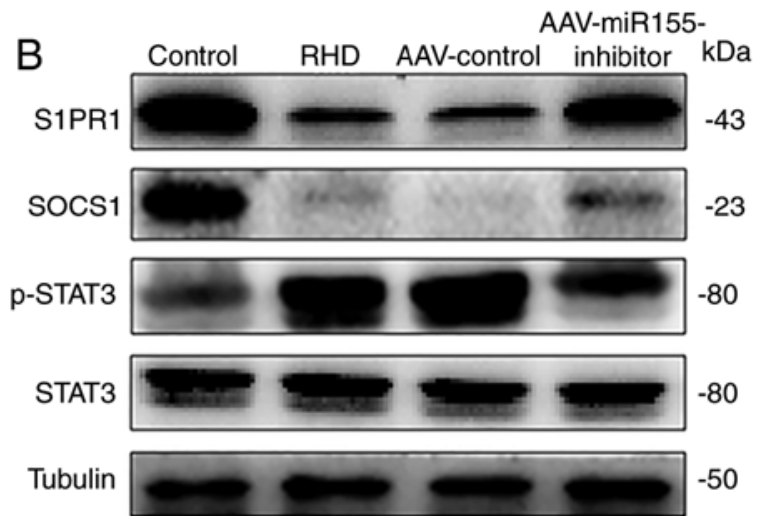

D

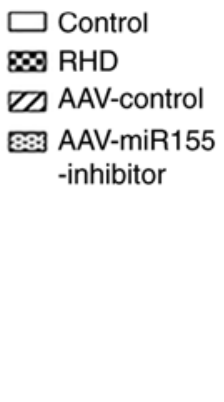

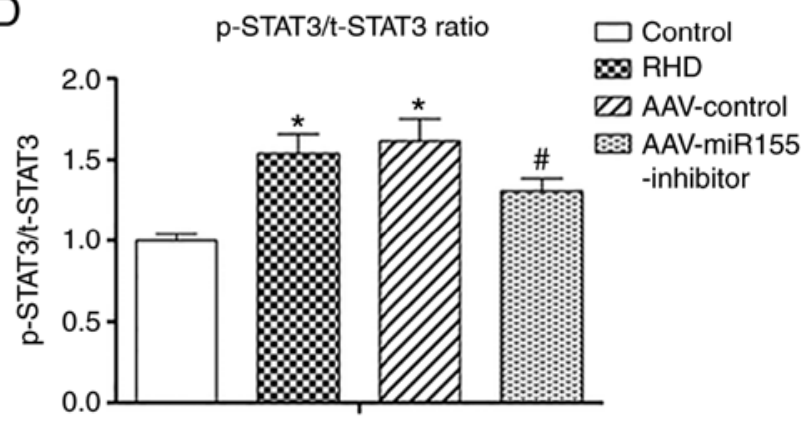

Figure 7. Reverse transcription-quantitative PCR and western blot analysis. (A) The relative mRNA expression of S1PR1, SOCS1 and STAT3 in the four groups. (B) Western blot analysis of S1PR1, SOCS1, STAT3 and p-STAT3 in the four groups. (C) The relative protein expression of S1PR1, SOCS1, STAT3 and p-STAT3 in the four groups. (D) The ratio of phosphorylated vs. total protein for STAT3. This figure shows that expression of S1PR1 and SOCS1 was increased and expression of p-STAT3 was decreased after AAV-injection. Data are shown as the mean \pm standard deviation; ${ }^{*} \mathrm{P}<0.05$ vs. the control group. ${ }^{\#} \mathrm{P}<0.05$ vs. the RHD group. S1PR1, sphingosine-1-phosphate receptor 1; SOCS1, suppressor of cytokine signaling 1; t-STAT3, total-signal transducer and activator of transcription 3; p-STAT3, phosphorylated-STAT3.

pretreatment also significantly attenuated the expression of IL-6 and IL-17 in the valve tissues and serum (P<0.05; Fig. 9).

\section{Discussion}

RHD affects $>30$ million people and kills 300,000 annually, but the specific pathophysiology and molecular mechanisms of this disease remain unknown. In recent decades, miRNAs have been shown to function in regulating various cellular pathways by targeting different genes. Several studies have reported that the expression of miRNAs is altered in patients with chronic RHD, including miR-205-3p, miR-1183 and miR-101. These miRNAs regulate the progression of RHD by targeting different pathways, such as IL-1 $\beta$ and TLR2 (17-19). The mechanism of action of miR-155-5p in RHD is still unclear, but scholars have reported that miR-155 is involved in autoimmunity, inflammation and fibrosis (20-22). Studies have shown that miR-155 plays a crucial role in rheumatoid arthritis and osteoarthritis (23). Inhibition of miR-155 attenuated the development of an abdominal aortic aneurysm by regulating macrophage inflammation (24). The paracrine activity of miR-155-enriched exosomes regulated fibroblast proliferation and inflammation in cardiac injury (22). Additionally, the inhibition of miR-155 attenuated inflammation after myocardial infarction through the SOCS1/nuclear factor- $\kappa B$ pathway (25). Knockout of miR-155 reduced the infarct size, inflammation and attenuated collagen deposition in acute myocardial infarction by targeting p53-inducible nuclear protein 1 (26). In the current study, the high expression of miR-155-5p in the RHD rat model was confirmed by RT-qPCR. With the inhibition of miR-155-5p induced by AAV pretreatment, decreased inflammation and fibrosis were observed in the valves. The miRNAs in exosomes, such as miR-let-7b (27) and miR-19a-3p (28), played a critical role in inflammation, autoimmunity and fibrosis. A high expression of miR-155-5p in serum exosomes was also observed, suggesting that exosomes might participate in RHD-induced valvular damage via the transfer of miR-155-5p. These results confirmed that miR-155-5p accelerated the progression of valvular damage and that the inhibition of miR-155-5p could alleviate this damage.

S1PR1, a G protein-coupled receptor, is one of the receptors for sphingosine 1-phosphate (S1P). The various functions of S1PR1 have been verified in recent decades. S1PR1 is involved in inflammation, autoimmunity and anti-fibrotic functions. FTY-720, a S1PR1 agonist, can significantly reduce joint destruction and inflammation in rheumatoid arthritis mice with osteoporosis (29). A study showed that the expression of S1PR1 in RA patients was significantly lower than in healthy control patients (30). The present authors have previously reported the downregulation of S1PR1 in an RHD rat model (10). In the current study, the dual luciferase assays confirmed that miR-155-5p directly targeted S1PR1 by binding to its 3' UTR in vitro. With the inhibition of miR-155-5p in the rat valves, the expression of S1PR1 was upregulated, as demonstrated by RT-qPCR, western blotting and immunohistochemistry in vivo. 


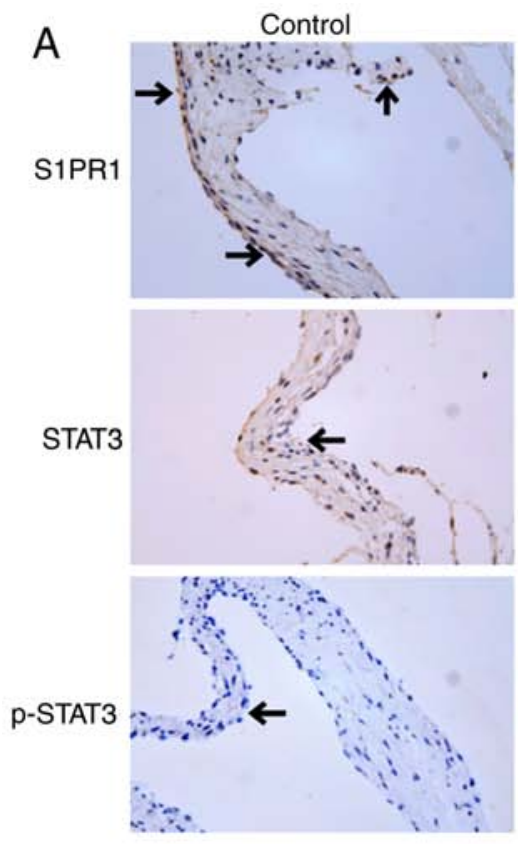

B
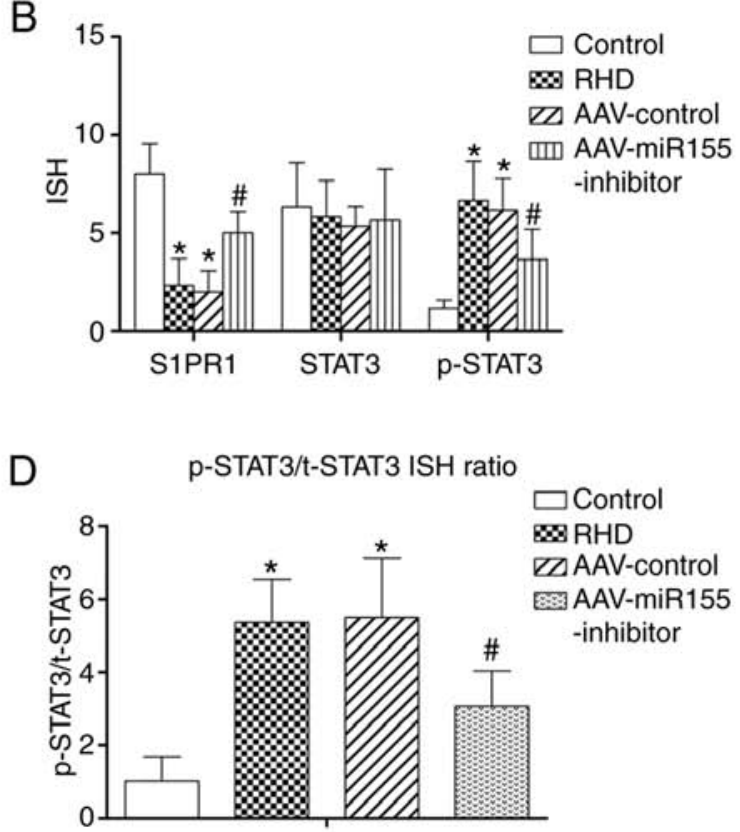
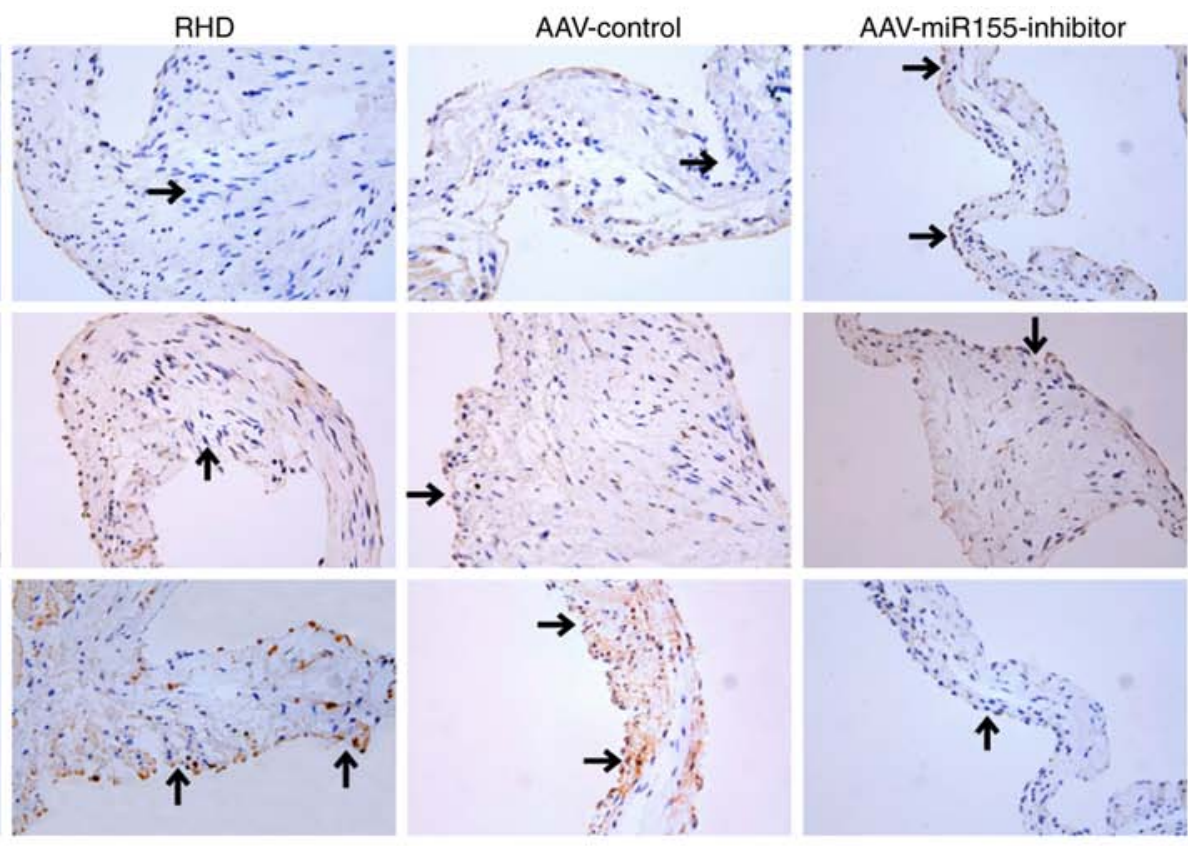

C

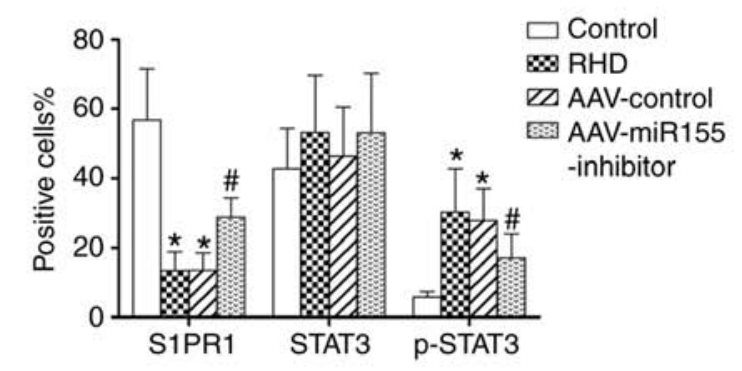

$\mathrm{E}$

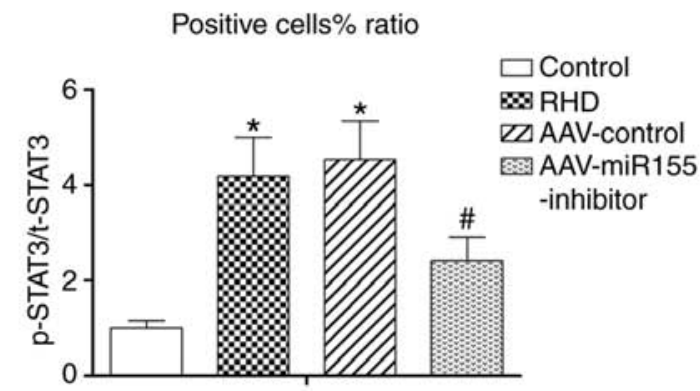

Figure 8. Immunohistochemistry analysis of S1PR1, STAT3 and p-STAT3 in valve tissues. (A) Immunohistochemistry for S1PR1, STAT3 and p-STAT3 in valve tissues; magnification, $\mathrm{x} 400$; the arrows represent positive cells. (B) The IHS. (C) The positive cells percentage. This figure shows that expression of S1PR1 was increased and expression of p-STAT3 was decreased after AAV-injection. (D) The ratio of phosphorylated vs. total protein for STAT3 (ISH score). (E) The ratio of phosphorylated vs. total protein for STAT3 (positive cells percentage). Data are shown as the mean \pm standard deviation; ${ }^{*} \mathrm{P}<0.05$ vs. the control group. ${ }^{~} \mathrm{P}<0.05$ vs. the RHD group. S1PR1, sphingosine-1-phosphate receptor 1; t-STAT3, total-signal transducer and activator of transcription 3; p-STAT3, phosphorylated STAT3; IHS, immunohistochemical score; RHD, rheumatic heart disease.

These results suggest that activation of the miR-155-5p/S1PR1 pathway promoted RHD-induced valvular damage and inhibition of this pathway attenuated this damage.

The STAT3 pathway plays a pivotal role in cancer inflammation and anti-tumor immunity $(31,32)$. Various previous studies have shown high expression of p-STAT3 in rheumatoid arthritis (5-7) and the STAT3 pathway was activated in permanent atrial fibrillation patients with rheumatic heart disease (33). The present study showed activation of the STAT3 pathway in an RHD rat model and the expression of the p-STAT3 protein was decreased with the inhibition of miR-155-5p. These results suggest a correlation between STAT3 activation and miR-155 upregulation, but the specific function of miR-155 in regulating the STAT3 signal pathway in RHD is unclear. Scholars have reported that SOCS1 is downregulated by miR-155 in non-small cell lung cancer (34), atopic dermatitis (35), ulcerative colitis (36), chronic neuropathic pain (37) and atherosclerosis (38). PDCD4 was reported to be regulated by miR155 via the SOCS1-STAT3 signaling pathway (8). The promotion of $\mathrm{T}$ helper 17 (Th17) cell differentiation induced by activation of the STAT3 pathway could be inhibited by an increase in 

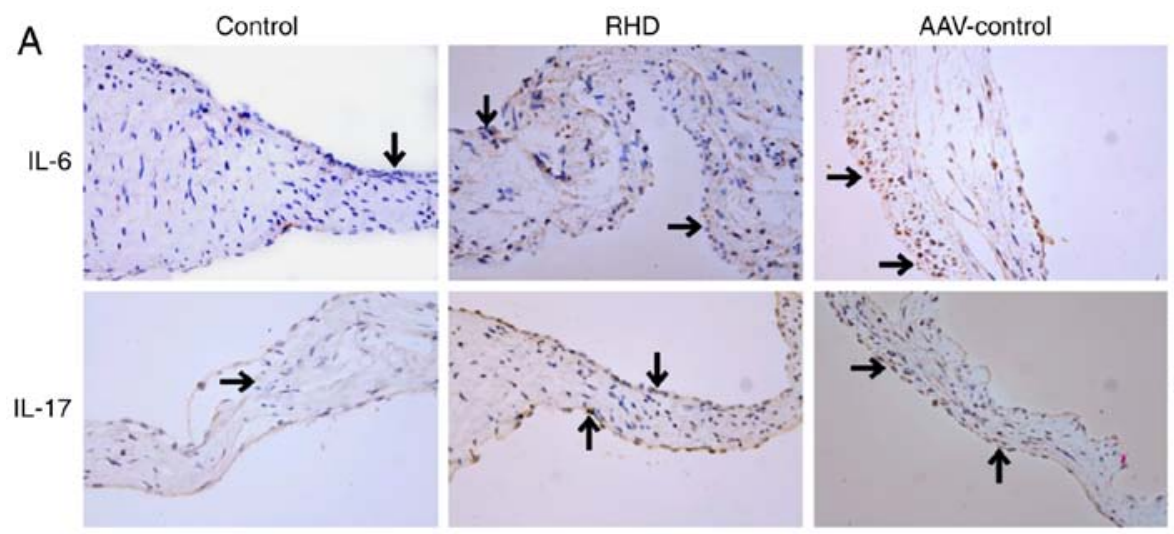

AAV-miR155-inhibitor
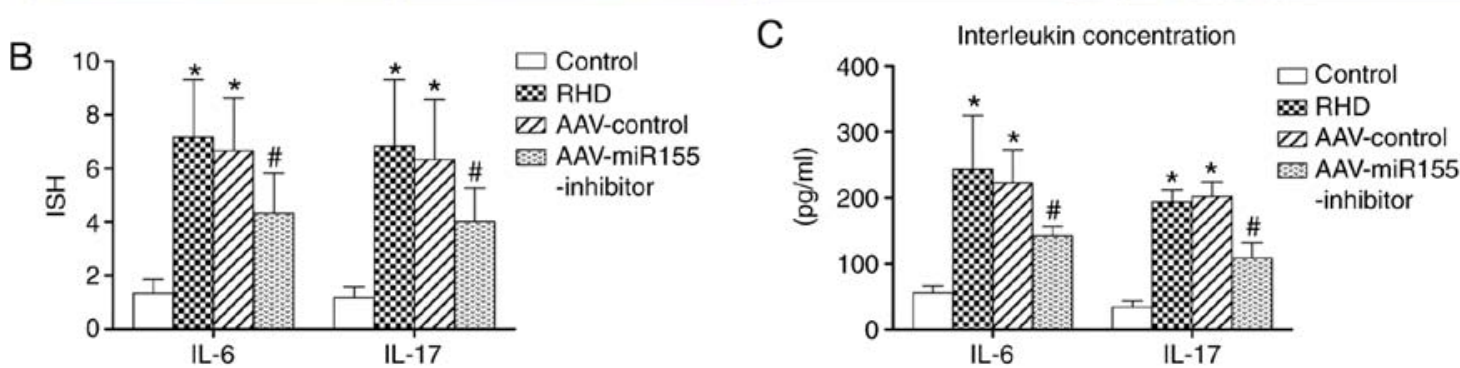

Figure 9. Cytokine expression. (A) Immunohistochemical analysis of IL-6 and IL-17 in valve tissues; magnification, $x 400$; the arrows indicates positive cells. (B) The IHS. (C) The concentrations of IL-6 and IL-17 in serum detected by ELISA. This figure shows that expression of IL-6 and IL-17 in serum and tissues was attenuated after AAV-injection. Data are shown as the mean \pm standard deviation; ${ }^{*} \mathrm{P}<0.05$ vs. the control group. ${ }^{~} \mathrm{P}<0.05$ vs. the RHD group. IL, interleukin; IHS, immunohistochemical score.

SOCS1 in rheumatoid arthritis (9). In the present study, the dual luciferase assay confirmed that miR-155-5p directly targeted SOCS1 by binding to its 3' UTR region in vitro. With the inhibition of miR-155-5p induced by AAV injection, the expression of SOCS1 was increased in vivo, as shown by RT-qPCR and western blotting. These results suggest that miR-155-5p regulated the SOCS1/STAT3 pathway and that the activation of the miR-155-5p/SOCS1/STAT3 pathway promoted RHD-induced valvular damage. Inhibition of this pathway could attenuate the progression of this damage.

Studies have demonstrated the pivotal role of IL-6 in immune system activation and inflammation in cancer $(39,40)$ and autoimmune diseases $(41,42)$. Liu et al (43) reported that the expression of IL- 6 and TNF- $\alpha$ was attenuated in miR-155-inhibited RA fibroblast-like synoviocytes. The IL-6/STAT3 axis is a key factor that regulates numerous autoimmune diseases (44). In the current study, the high expression of IL- 6 in the valves and serum was detected by immunohistochemistry and ELISA. With the inhibition of miR-155-5p, the expression of IL-6 in valves and serum decreased. Consistent with these results, the upregulation of IL-6 induced by the upregulation of miR-155 also participated in the activation of the STAT3 signal pathway. This miR-155-5p/IL-6/STAT3 pathway also promoted RHD-induced valvular damage and inhibition of this pathway alleviated the progression of valvular damage.

One study reported that the serum level of IL-17 was higher in rheumatic mitral stenosis patients (45) and the biological function of proinflammation in rheumatic disease has been confirmed by numerous scholars $(46,47)$. miR-155 promotes the development of Th17 cell and Th1 cell subsets (21). Studies have reported the essential roles of miR-155 in the immune response to Streptococcus pneumoniae (48) and Th17 cell differentiation (35). The authors previously reported that Th17 cell-associated cytokines were significantly higher in patients with RHD, including IL-17 and IL-21 (11). In the present study, the high expression of IL-17 in serum and valve tissue was suppressed by the downregulation of miR-155-5p. Consistent with this finding, the present data suggested that miR-155-5p promoted Th17 cell differentiation and participated in the progression of RHD.

However, some important limitations should be mentioned in this study. Firstly, valvular inflammation and fibrosis after upregulating of miR-155-5p were not detected. Secondly, experiments in cell lines were not performed, which would provide another layer of tests for the present study. Thirdly, the expression of miR-155-5p in serum exosomes after AAV-injection and differential expressions of other miRNAs and proteins in serum exosomes after valvular damage were not detected, it would be valuable to measure the expression in an RHD rat model in the future. In addition, the relative mRNA expression of FSP1 and Col3a1 was used as fibrosis molecular markers, but the protein expression was not detected.

The current study clarified that miR-155-5p in serum exosome and valve tissues was upregulated in a GAS-induced RHD rat model. Further study showed that miR-155-5p regulated the progress of RHD-induced valvular damage by regulating multiple signaling pathways. miR-155-5p directly suppressed S1PR1 expression and miR-155-5p also directly suppressed the expression of SOCS1 and then activated STAT3 phosphorylation. miR-155-5p promoted the expression of IL-6 and then activated STAT3 phosphorylation. miR-155-5p also promoted the differentiation of Th17 cells. Thus, miR-155-5p played a critical role in RHD progression. 


\section{Acknowledgements}

Not applicable.

\section{Funding}

The present study was supported by the National Natural Science Foundation of China (grant no. 81660069), Guangxi Key Laboratory BaseofPrecisionMedicineinCardio-cerebrovascular Disease Control (grant no. 17-259-85) and Prevention and Guangxi Clinical Research Center for Cardio-cerebrovascular Diseases (grant no. AD17129014).

\section{Availability of data and materials}

All data generated or analyzed during this study are included in this published article.

\section{Authors' contributions}

$\mathrm{ZZ}$ and $\mathrm{FH}$ conceived and designed the study. AC and JW participated in the experimental design. AC, JW, CL and SX performed the experiments. AC, BL and YW analyzed the data. AC wrote the manuscript and all authors contributed to the final manuscript.

\section{Ethics approval and consent to participate}

Protocols involving animals were approved by the Medical Ethics Committee of the First Affiliated Hospital of Guangxi Medical University (permit no. 2016-KY-201).

\section{Patient consent for publication}

Not applicable.

\section{Competing interests}

The authors declare that they have no competing interests.

\section{References}

1. Watkins DA, Johnson CO, Colquhoun SM, Karthikeyan G Beaton A, Bukhman G, Forouzanfar MH, Longenecker CT, Mayosi BM, Mensah GA, et al: Global, regional, and national burden of rheumatic heart disease, 1990-2015. N Engl J Med 377: 713-722, 2017.

2. Marijon E, Mirabel M, Celermajer DS and Jouven X: Rheumatic heart disease. Lancet 379: 953-964, 2012.

3. Guilherme L and Kalil J: Rheumatic fever and rheumatic heart disease: Cellular mechanisms leading autoimmune reactivity and disease. J Clin Immunol 30: 17-23, 2010.

4. Turkson J and Jove R: STAT proteins: Novel molecular targets for cancer drug discovery. Oncogene 19: 6613-6626, 2000.

5. Gao W, McCormick J, Connolly M, Balogh E, Veale DJ and Fearon U: Hypoxia and STAT3 signalling interactions regulate pro-inflammatory pathways in rheumatoid arthritis. Ann Rheum Dis 74: 1275-1283, 2015.

6. Liu J, Fei D, Xing J and Du J: MicroRNA-29a inhibits proliferation and induces apoptosis in rheumatoid arthritis fibroblast-like synoviocytes by repressing STAT3. Biomed Pharmacother 96 173-181, 2017.

7. Lee SH, Kim EK, Kwon JE, Lee JK, Lee D, Kim SY, Seo HB, Na HS, Jung K, Kwok SK, et al: Ssu72 attenuates autoimmune arthritis via targeting of STAT3 signaling and Th17 activation. Sci Rep 7: 5506, 2017.
8. Ye J, Guo R, Shi Y, Qi F, Guo C and Yang L: miR-155 regulated inflammation response by the SOCS1-STAT3-PDCD4 axis in atherogenesis. Mediators Inflamm 2016: 8060182, 2016.

9. Jahreis S, Kuhn S, Madaj AM, Bauer M and Polte T: Mold metabolites drive rheumatoid arthritis in mice via promotion of IFN-gamma- and IL-17-producing T cells. Food Chem Toxicol 109: 405-413, 2017.

10. Wu XD, Zeng ZY, Gong DP, Wen JL and Huang F: Potential involvement of S1PR1/STAT3 signaling pathway in cardiac valve damage due to rheumatic heart disease. Biotech Histochem 94: 398-403, 2019.

11. Wen Y, Zeng Z, Gui C, Li L and Li W: Changes in the expression of Th17 cell-associated cytokines in the development of rheumatic heart disease. Cardiovasc Pathol 24: 382-387, 2015.

12. Teker E, Akadam-Teker AB, Ozturk O, Eronat AP, Yalin K, Golcuk SE and Bugra Z: Association between the interferon gamma $874 \mathrm{~T} / \mathrm{A}$ polymorphism and the severity of valvular damage in patients with rheumatic heart disease. Biochem Genet 56: 225-234, 2018.

13. Gorton D, Govan B, Olive C and Ketheesan N: B- and T-cell responses in group a streptococcus M-protein- or Peptide-induced experimental carditis. Infect Immun 77: 2177-2183, 2009.

14. Friedrichs K, Gluba S, Eidtmann H and Jonat W: Overexpression of p53 and prognosis in breast cancer. Cancer 72: 3641-3647, 1993.

15. Livak KJ and Schmittgen TD: Analysis of relative gene expression data using real-time quantitative PCR and the 2(-Delta Delta C(T)) method. Methods 25: 402-408, 2001.

16. Purushothaman KR, Purushothaman M, Turnbull IC, Adams DH, Anyanwu A, Krishnan P, Kini A, Sharma SK, O'Connor WN and Moreno PR: Association of altered collagen content and lysyl oxidase expression in degenerative mitral valve disease. Cardiovasc Pathol 29: 11-18, 2017.

17. Lu Q, Sun Y, Duan Y, Li B, Xia J, Yu S and Zhang G: Comprehensive microRNA profiling reveals potential augmentation of the IL1 pathway in rheumatic heart valve disease. BMC Cardiovasc Disord 18: 53, 2018.

18. Li N, Lian J, Zhao S, Zheng D, Yang X, Huang X, Shi X, Sun L, Zhou Q, Shi H, et al: Detection of differentially expressed MicroRNAs in rheumatic heart disease: miR-1183 and miR-1299 as potential diagnostic biomarkers. Biomed Res Int 2015: 524519, 2015.

19. Dong H, Sun Y, Shan F, Sun Q and Yang B: Down-regulation of miR-101 contributes to rheumatic heart disease through up-regulating TLR2. Med Sci Monit 21: 1500-1506, 2015.

20. Thai TH, Calado DP, Casola S, Ansel KM, Xiao C, Xue Y, Murphy A, Frendewey D, Valenzuela D, Kutok JL, et al: Regulation of the germinal center response by microRNA-155. Science 316: 604-608, 2007.

21. O'Connell RM, Kahn D, Gibson WS, Round JL, Scholz RL, Chaudhuri AA, Kahn ME, Rao DS and Baltimore D: MicroRNA-155 promotes autoimmune inflammation by enhancing inflammatory $\mathrm{T}$ cell development. Immunity 33: 607-619, 2010.

22. Wang C, Zhang C, Liu L, A X, Chen B, Li Y and Du J: Macrophage-derived mir-155-containing exosomes suppress fibroblast proliferation and promote fibroblast inflammation during cardiac injury. Mol Ther 25: 192-204, 2017.

23. Kriegsmann M, Randau TM, Gravius S, Lisenko K, Altmann C, Arens N and Kriegsmann J: Expression of miR-146a, miR-155, and miR-223 in formalin-fixed paraffin-embedded synovial tissues of patients with rheumatoid arthritis and osteoarthritis. Virchows Arch 469: 93-100, 2016.

24. Zhang Z, Liang K, Zou G, Chen X, Shi S, Wang G, Zhang K, $\mathrm{Li} \mathrm{K}$ and Zhai S: Inhibition of miR-155 attenuates abdominal aortic aneurysm in mice by regulating macrophage-mediated inflammation. Biosci Rep 38: BSR20171432, 2018.

25. Hu J, Huang CX, Rao PP, Cao GQ, Zhang Y, Zhou JP, Zhu LY, Liu MX and Zhang GG: MicroRNA-155 inhibition attenuates endoplasmic reticulum stress-induced cardiomyocyte apoptosis following myocardial infarction via reducing macrophage inflammation. Eur J Pharmacol 857: 172449, 2019.

26. He W, Huang H, Xie Q, Wang Z, Fan Y, Kong B, Huang D and Xiao Y: MiR-155 knockout in fibroblasts improves cardiac remodeling by targeting tumor protein p53-inducible nuclear protein 1. J Cardiovasc Pharmacol Ther 21: 423-435, 2016.

27. Kim SJ, Chen Z, Essani AB, Elshabrawy HA, Volin MV, Volkov S, Swedler W, Arami S, Sweiss N and Shahrara S: Identification of a novel toll-like receptor 7 endogenous ligand in rheumatoid arthritis synovial fluid that can provoke arthritic joint inflammation. Arthritis Rheumatol 68: 1099-1110, 2016. 
28. Gollmann-Tepeköylü C, Pölzl L, Graber M, Hirsch J Nägele F, Lobenwein D, Hess MW, Blumer MJ, Kirchmair E, Zipperle J, et al: miR-19a-3p containing exosomes improve function of ischemic myocardium upon shock wave therapy. Cardiovasc Res: Aug 13, 2019 (Epub ahead of print).

29. Kikuta J, Iwai K, Saeki Y and Ishii M: S1P-targeted therapy for elderly rheumatoid arthritis patients with osteoporosis. Rheumatol Int 31: 967-969, 2011.

30. Choi HS, Kim KH, Jin S, Kim J, Yoo I, Pack SP, Ha UH, Park TW, Choi SA, Yuk SH, et al: Decreased expression of sphingosine-1-phosphate receptor 1 in the blood leukocyte of rheumatoid arthritis patients. Immune Netw 18: e39, 2018.

31. Yu H, Pardoll D and Jove R: STATs in cancer inflammation and immunity: A leading role for STAT3. Nat Rev Cancer 9: 798-809, 2009.

32. Yu H, Kortylewski M and Pardoll D: Crosstalk between cancer and immune cells: Role of STAT3 in the tumour microenvironment. Nat Rev Immunol 7: 41-51, 2007.

33. Xue XD, Huang JH and Wang HS: Angiotensin II activates signal transducers and activators of transcription 3 via Racl in the atrial tissue in permanent atrial fibrillation patients with rheumatic heart disease. Cell Biochem Biophys 71: 205-213, 2015.

34. Xue X, Liu Y, Wang Y, Meng M, Wang K, Zang X, Zhao S, Sun X, Cui L, Pan L and Liu S: miR-21 and miR-155 promote non-small cell lung cancer progression by downregulating SOCS1, SOCS6 and PTEN. Oncotarget 7: 84508-84519, 2016.

35. Ma L, Xue HB, Wang F, Shu CM and Zhang JH: MicroRNA-155 may be involved in the pathogenesis of atopic dermatitis by modulating the differentiation and function of T helper type 17 (Th17) cells. Clin Exp Immunol 181: 142-149, 2015.

36. Pathak S, Grillo AR, Scarpa M, Brun P, D'Incà R, Nai L, Banerjee A, Cavallo D, Barzon L, Palù G, et al: miR-155 modulates the inflammatory phenotype of intestinal myofibroblasts by targeting SOCS1 in ulcerative colitis. Exp Mol Med 47: e164, 2015.

37. Tan Y, Yang J, Xiang K, Tan Q and Guo Q: Suppression of microRNA-155 attenuates neuropathic pain by regulating SOCS1 signalling pathway. Neurochem Res 40: 550-560, 2015

38. Yang Y, Yang L, Liang $X$ and Zhu G: MicroRNA-155 promotes atherosclerosis inflammation via targeting SOCS1. Cell Physiol Biochem 36: 1371-1381, 2015.
39. Scheller J, Chalaris A, Schmidt-Arras D and Rose-John S: The pro- and anti-inflammatory properties of the cytokine interleukin-6. Biochim Biophys Acta 1813: 878-888, 2011.

40. Hodge DR, Hurt EM and Farrar WL: The role of IL-6 and STAT3 in inflammation and cancer. Eur J Cancer 41: 2502-2512, 2005.

41. Narazaki $M$, Tanaka $\mathrm{T}$ and Kishimoto $\mathrm{T}$ : The role and therapeutic targeting of IL-6 in rheumatoid arthritis. Expert Rev Clin Immunol 13: 535-551, 2017.

42. Tanaka T, Narazaki $M$ and Kishimoto T: IL-6 in inflammation, immunity, and disease. Cold Spring Harb Perspect Biol 6: a016295, 2014.

43. Liu N, Feng X, Wang W, Zhao X and Li X: Paeonol protects against TNF- $\alpha$-induced proliferation and cytokine release of rheumatoid arthritis fibroblast-like synoviocytes by upregulating FOXO3 through inhibition of miR-155 expression. Inflamm Res 66: 603-610, 2017.

44. Camporeale A and Poli V: IL-6, IL-17 and STAT3: A holy trinity in auto-immunity? Front Biosci (Landmark Ed) 17: 2306-2326, 2012.

45. Bilik MZ, Kaplan I, Polat N, Akil MA, Akyüz A, Acet H, Yüksel M, İnci Ü, Kayan F and Toprak N: Serum levels of IL-17 and IL-23 in patients with rheumatic mitral stenosis. Medicine (Baltimore) 95: e3562, 2016.

46. Volin MV and Shahrara S: Role of TH-17 cells in rheumatic and other autoimmune diseases. Rheumatology (Sunnyvale) 1: 2169, 2011.

47. Al-Saadany HM, Hussein MS, Gaber RA and Zaytoun HA: Th-17 cells and serum IL-17 in rheumatoid arthritis patients: Correlation with disease activity and severity. The Egyptian Rheumatologist 38: 1-7, 2016.

48. Verschoor CP, Dorrington MG, Novakowski KE, Kaiser J, Radford K, Nair P, Anipindi V, Kaushic C, Surette MG and Bowdish DM: MicroRNA-155 is required for clearance of Streptococcus pneumoniae from the nasopharynx. Infect Immun 82: 4824-4833, 2014.

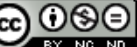

This work is licensed under a Creative Commons Attribution-NonCommercial-NoDerivatives 4.0 International (CC BY-NC-ND 4.0) License. 